\section{JURNAL ABDIMAS

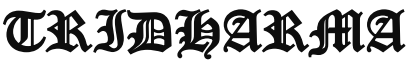

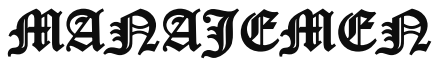

P-ISSN 2615-6849, E-ISSN 2622-3686

Jurnal ABDIMAS Vol. 1,No. 3,September 2020,Hal (75-84)

@ Prodi Manajemen Fakultas Ekonomi Universitas Pamulang

Email: abdimasjurnal.unpam@gmail.com Telp: (021) 741-2566

\title{
UPGRADE LITERASI KEUANGAN UNTUK MENINGKATKAN KUALITAS KEUANGAN DI MASA NEW NORMAL
}

Wirawan Suryanto, Jeni Irnawati, Vega Anismadiyah, Vidya A Rismanty, Hadijah Febriana,

Dosen Manajemen Universitas Pamulang

Emaildosen02244@unpam.ac.id, dosen02228@unpam.ac.id, dosen02218@unpam.ac.id, dosen02270@unpam.ac.id, dosen02182@unpam.ac.id

\begin{abstract}
ABSTRAK
Pengelolaan keuangan yang sehat merupakan tanggung jawab bagi masing masing individu. Namun minimnya literasi keuangan yang dimiliki oleh mitra kerjasama membuat pengelolaan keuangan yang kurang baik. Mitra kerjasama dalam kegiatan kemitraan masyarakat ini adalah masyarakat umum yang ingin menambah keilmuan melalui seminar yang diadakan. Di tengah pandemi yang sedang terjadi maka dapat dimanfaatkan sebagai waktu luang agar menambah pengetahuan. Mitra yang terlibat dalam kegiatan ini adalah dosen Universitas Pamulang sebagi narasumber. Berdasarkan observasi awal yang dilakukan, selama ini masyarakat hanya mendapat pengetahuan berdasarkan apa yang mereka tahu saja dalam hal uang dan transaksi keuangan. Namun, literasi maupun inklusi Pasar Modal menurut Survei Nasional Literasi dan Inklusi Keuangan 2016 oleh Otoritas Jasa Keuangan (OJK) masih sangat jauh dibawah angka industri sektor keuangan lainnya seperti perbankan, asuransi, dana pensiun, lembaga pembiayaan dan pegadaian. Hal tersebut yang melatarbelakangi kegiatan pengabdian kepada masyarakat yang dilakukan oleh dosen Universitas Pamulang, khususnya kegiatan literasi keuangan dan memperbaiki literasi keuangan masyarakat dan juga kesejahteraan masyarakat dari sisi keuangan. Beberapa tahap keuangan yang harus di capai dalam memperoleh kesejahteraan keuangan. Tahap yang pertama adalah membuat suatu rencana keuangan seoptimal mungkin sesuai dengan kondisi finansial masing-masing. Tahap kedua adalah mengurangi hutang. Tahap ketiga yaitu menyiapkan dana darurat. Tahap keempat ialah mulai berinvestasi. Tahap kelima adalah membangun aset aktif. Tahap keenam yaitu menerima penghasilan pasif. Tahap terakhir ialah sejahtera. Bila keenam tahapan sebelumnya dapat dilaksanakan dengan baik, maka kesejahteraan akan bisa dicapai oleh siapapun. Target luaran yang diharapkan dari pelaksanaan kegiatan ini adalah paper yang terpublikasi.
\end{abstract}

Kata Kunci : Literasi Keuangan, Pengabdian Kepada Masyarakat, New Normal 


\section{JURNAL ABDIMAS

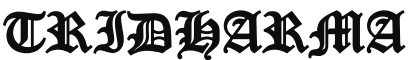

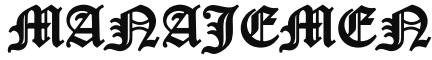

P-ISSN 2615-6849, E-ISSN 2622-3686

Jurnal ABDIMAS Vol. 1,No. 3,September 2020,Hal (75-84)

@ Prodi Manajemen Fakultas Ekonomi Universitas Pamulang

Email: abdimasjurnal.unpam@gmail.com Telp: (021) 741-2566

\begin{abstract}
Financial management is the responsibility of each individual. But the lack of financial literacy possessed by collaborative partners makes financial management unfavorable. Cooperation partners in community partnership activities are the general public who want to increase knowledge through seminars held. In the midst of a pandemic that is happening, it can be used as free time to increase knowledge. The partners involved in this activity are Pamulang University lecturers as resource persons. Based on preliminary observations made, so far people only get knowledge based on what they know only in terms of money and financial transactions. However, capital market literacy and inclusion according to the 2016 National Financial Literacy and Inclusion Survey by the Financial Services Authority (OJK) are still far below the figures of other financial sector industries such as banking, insurance, pension funds, financial institutions and pawnshops. This is the background of community service activities carried out by Pamulang University lecturers, specifically financial literacy activities and improving public financial literacy and also public welfare in financial terms. Some financial stages that must be achieved in obtaining financial welfare. The first stage is to make a financial plan as optimal as possible in accordance with their respective financial conditions. The second stage is reducing debt. The third stage is preparing an emergency fund. The fourth step is to start investing. The fifth stage is building active assets. The sixth stage is receiving passive income. The last step is prosperity. If the previous six stages can be implemented well, then welfare will be achieved by anyone. The expected output target of the implementation of this activity is a published paper.
\end{abstract}

\title{
Keywords: Financial Literacy, Community Service, New Normal
}

\section{PENDAHULUAN}

Pengelolaan keuangan merupakan tanggung jawab setiap individu terhadap keuangannya karena pengelolaan keuangan berkaitan erat dengan kebutuhan hidup sehari-hari. Kehidupan modern seperti zaman ini, kebutuhan dan keinginan seseorang sudah semakin kompleks. Hal ini membuat pola hidup konsumtif seseorang menjadi tidak proporsional, seperti melakukan pembelian yang secara tiba-tiba tanpa pertimbangan kedepannya.

Setiap individu harus bisa mengatur keuangan mereka sendiri dengan baik. Maka dari itu mereka harus dibekali dengan pengetahuan keuangan yang baik agar menciptakan keselarasan antara pemasukan yang mereka peroleh dengan pengeluaran atau konsumsi yang mereka butuhkan, karena tidak semua individu memiliki 


\section{JURNAL ABDIMAS

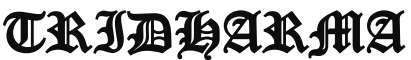

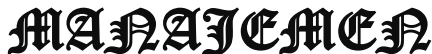

P-ISSN 2615-6849, E-ISSN 2622-3686

Jurnal ABDIMAS Vol. 1,No. 3,September 2020,Hal (75-84)

@ Prodi Manajemen Fakultas Ekonomi Universitas Pamulang

Email: abdimasjurnal.unpam@gmail.com Telp: (021) 741-2566 pendapatan dan keperluan yang sama. Kesulitan keuangan tidak hanya disebabkan oleh pengaruh pendapatan, namun dapat juga dipengaruhi oleh kesalahan pengelolaan keuangan, seperti tidak adanya perencanaan keuangan.

Pengelolaan keuangan dapat diukur dengan tingkat literasi keuangan yang dimiliki oleh setiap individu. Secara keseluruhan literasi keuangan dapat diartikan sebagai seperangkat keterampilan dan pengetahuan yang dapat membantu seseorang dalam mengelola keuangan untuk mencapai kehidupan yang lebih sejahtera dimasa depan. Dalam beberapa tahun terakhir, isu mengenai literasi keuangan telah menjadi salah satu fokus kebijakan pemerintah diberbagai negara tak terkecuali di Indonesia.

Literasi pada era sekarang tidaklah terbatas hanya pada kemampuan serta kecakapan dalam membaca, menulis, dan berhitung. Menurut Kemendikbud (2016) pada Forum Ekonomi Dunia 2015 dengan tema "Visi Baru untuk Pendidikan: membina Pembelajaran Sosial dan Emosionalmelalui Teknologi", menyebutkan literasi dasar sebagai salah satu keterampilan utuh abad 21. Literasi dasar ini mencakup beberapa komponen, diantaranya kemampuan baca dan berhitung, sains, teknologi informasi, dan komunikasi(TIK), keuangan, budaya, dan kewarganegaraan. Sejalan dengan hal tersebut, Kemendikbud membuat program GLN (Gerakan Literasi Nasional) sejak tahun 2016.

Di Indonesia, sebagai salah satu negara berkembang, pendidikan literasi keuangan masih menjadi sesuatu yang sangat jarang dilakukan. Baik di lingkup keluarga ataupun di sekolah, pemberian pendidikan tentang literasi keuangan masih belum dilakukan secara serius dan terencana dan dianggap sebagai bagian yang tidak penting. Keluarga masih memandang tabu ketika membicarakan segala sesuatu tentang uang di hadapan anak-anak, hal ini menyebabkan anak-anak menjadi tidak merasa penting untuk menyiapkan diri untuk mempelajari pengelolaan keuangan sejak dini. Hal ini menyebabkan mengapa pengetahuan, sikap, dan keterampilan tentang kesehatan finansial keluarga belum mendapat porsi yang cukup pada kurikulum pendidikan dasar dan menengah. Oleh karena itu, muncul pandangan bahwa literasi finansial bukan merupakan kecakapan hidup (life skills) yang harus dimiliki oleh seluruh masyarakat indonesia.

Menurut Otoritas Jasa Keuangan (2017), hanya sekitar 29,7 persen masyarakat yang telah mampu atau paham literasi keuangan, hal ini memprihatinkan, yang di lain sisi hal ini menjadi pemicu dari banyaknya masalah yang dihadapi oleh masyarakat. Pendidikan literasi keuangan 

JURNAL ABDIMAS
P-ISSN 2615-6849, E-ISSN 2622-3686

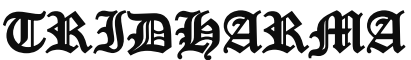
Jurnal ABDIMAS Vol. 1,No. 3,September 2020,Hal (75-84)

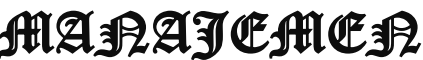

ada anak bukan hanya sekedar memperkenalkan nominal uang saja, namun merupaka suatu konsep tentang kecakapan dalam mengelola serta mengontrol keuangan secara bijak. Anak pun akan dididik untuk dapat membedakan antara kebututuhan dengan keinginan dalam menggunakan uangnya.

Melakukan edukasi kesadaran keuangan (financial literacy) diperlukan sedini mungkin. Pembiasaan hal baik, biasanya dilakukan sedini mungkin agar hal baik tersebut menjadi sebuah pembiasaan yang pada akhirnya mempengaruhi dalam perilaku dan pengambilan keputusan. Demikian pula mengenai pembiasaan dalam pengelolaan keuangan. Literasi keuangan sangat baik jika diterapkan sejak dini, karena akan membentuk generai muda penerus bangsa yang tidak konsumtif serta dapat mengelola keuangan pribadi dengan bijak.

Pada literasi keuangan semua masalah yang ada di atas akan berusahaan di mimalisir, terutama pada kebiasaan. Karena inti dari literasi keuangan adalah menanamkan kebiasaan yang baik yang akan membuat pribadi yang memiliki kebiasaan yang baik dan membawa kebiasaan yang baik tersebut untuk dapat memberi manfaaat untuk sekitarnya. Oleh karena itu kami tertarik untuk melakukan pengabdian kepada masyarakat dengan judul "Upgrade Literasi Keuangan Untuk
Meningkatkan Kualitas Keuangan Di Masa New Normal”.

\section{RUMUSAN MASALAH}

Rumusan masalah yang akan di pecahkan melalui program ini pada dasarnya tidak lepas dari ruang lingkup masalah diatas, adapun perumusan masalah dalam kegiatan ini adalah:

1. Bagaimana upaya meningkatkan kualitas literasi keuangan dalam menghadapi masa era new normal ?

2. Faktor yang mendukung peningkatkan kualitas literasi keuangan dalam menghadapi masa era new normal ?

\section{TUJUAN PELAKSANAAN}

Adapun tujuan dari pengabdian masyarakat ini adalah sbagai berikut:

1. Untuk mengetahui upaya - upaya apa saja yang dapat meningkatkan kualitas literasi keuangan dalam menghadapi era new normal.

2. Untuk mengetahui faktor - faktor apa saja yang dapat meningkatkan kualitas literasi keuangan dalam menghadapi era new normal.

\section{TINJAUAN PUSTAKA}

\section{Literasi}

Menurut Soetiono \& Setiawan (2018:03) "Literasi merupakan kemampuan individu untuk menggunakan segenap potensi dan keterampilan yang dimiliki dalam hidupnya”. 


\section{JURNAL ABDIMAS

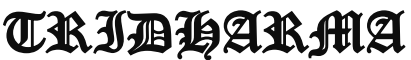

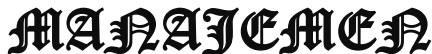

P-ISSN 2615-6849, E-ISSN 2622-3686

Jurnal ABDIMAS Vol. 1,No. 3,September 2020,Hal (75-84)

@ Prodi Manajemen Fakultas Ekonomi Universitas Pamulang

Email: abdimasjurnal.unpam@ gmail.com Telp: (021) 741-2566

\section{Keuangan}

Menurut Gitman (2003:04) menyatakan : Finance can be defined as the art and science of managing money. Virtually all individuals and organizations earn or raise money and spend or invest money. Finance is concerned with the process, institutions, markets, and instrument involved in the transfer of money among individuals, businesses, and governments. Pernyataan yang dikemukakan oleh Gitman memiliki makna bahwa keuangan dapat didefinisikan sebagai suatu seni dan ilmu pengetahuan dari pengelolaan uang. Sesungguhnya setiap individu dan organisasi menghasilkan uang dan membelanjakan atau mengivestasikan uang. Keuangan berhubungan dengan proses, institusi, pasar, dan instrumen yang terlibat dalam perpindahan atau transfer uang antar individu, bisnis, dan pemerintah.

\section{Literasi Keuangan}

Dalam Strategi Nasional Literasi Keuangan Indonesia (2017) menyatakan "Literasi keuangan adalah pengetahuan, keterampilan dan keyakinan yang mempengaruhi sikap dan perilaku untuk meningkatkan kualitas pengambilan keputusan dan pengelolaan keuangan dalam rangka mencapai kesejahteraan". Menurut Bhushan \& Medury (2013:155) menyatakan "Financial literacy is the ability to make informed judgments and to take effective decisions regarding the use and management of money. Financial literacy enables individuals to improve their overall well-being". Pernyataan yang dikemukakan oleh Bhushan \& Medury memiliki makna bahwa literasi keuangan adalah kemampuan untuk membuat penilaian berdasarkan informasi dan untuk mengambil keputusan yang efektif mengenai penggunaan dan pengelolaan uang, literasi keuangan memungkinkan individu untuk meningkatkan kesejahteraan mereka secara keseluruhan.

\section{Faktor - Faktor Yang}

Mempengaruhi Literasi Keuangan Menurut Otoritas Jasa Keuangan (OJK, 2017) faktor-faktor yang mempengaruhi literasi keuangan yaitu jenis kelamin, tingkat pendidikan, tingkat pendapatan. Menurut Widayati (2012) faktor-faktor yang mempengaruhi literasi keuangan yaitu status sosial ekonomi orang tua, pendidikan pengelolaan keuangan keluarga, pembelajaran keuangan di perguruan tinggi negeri.

\section{METODE PELAKSANAAN}

Tim PKM memberikan pegajaran Literasi Keuangan melalui brainstorming metode dan melakukan pendampingan kepada masyarakat

Ketika menggunakan metode brainstorming, ada 4 hal yang perlu di 


\section{JURNAL ABDIMAS

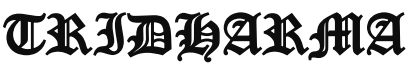

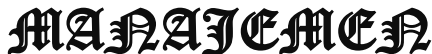

P-ISSN 2615-6849, E-ISSN 2622-3686

Jurnal ABDIMAS Vol. 1,No. 3,September 2020,Hal (75-84)

@ Prodi Manajemen Fakultas Ekonomi Universitas Pamulang

Email: abdimasjurnal.unpam@ gmail.com Telp: (021) 741-2566 perhatikan yaitu: 1) tidak boleh ada komentar negative dari siapapun dalam kelompok, 2) keadaan siuasi yang bebas tidak terkungkung,3) kuantitas ide sangat diinginkan, makin banyak ide akan semakin baik. 4) ide- ide dari orang lain dapat digunakan untuk memperbaiki dan menghasilkan ide baru.

Beberapa solusi lain yang di berikan kepada para peserta untuk meningkatkan literasi keuangannya adalah dengan melakukan sesi sharing. Dalam sesi ini dijelakan mengenai instrumen apa saja yang dapat digunakan dalam mencapai kesejahteraan dalam hal finansial. Kemudian menumbuhkan rasa ingin tahu yang akan menarik minat para peserta untuk lebih dalam mengetahui tentang literasi keuangan yang akan memperbaiki kualitas keuangan para peserta dalam menghadapi era new normal.

\section{Metode Pelaksanaan Kegiatan}

Untuk melaksanakan kegiatan tersebut digunakan beberapa meode pelatihan, yaitu:

Metode Ceramah/Presentasi.

Metode ceramah/presentasi dipilih untuk memberikan penjelasan tentang:

a. Menigkatkan kualitas literasi keuangan

b. Presentasi mengenai materi tahap untuk mencapai kesejahteraan keuangan
Metode Tanya Jawab Metode.

Tanya jawab sangat penting bagi para peserta pelatihan. Metode ini memungkinkan Siswa menggali pengetahuan sebanyak-banyaknya tentang Meningkatkan Kualitas Litersai Keuangan.

Sharing Session Tentang Meningkatkan Kualitas Litersai Keuangan.

Sharing session ini diberikan kepada para peserta pelatihan dalam memberikan masukan dan bimbingan untuk mempraktekan materi yang diperoleh. Harapannya, peserta pelatihan dapat menguasai materi pelatihan yang diterima

\section{HASIL DAN PEMBAHASAN}

TIM PKM Universitas Pamulang membagi ilmu kepada mahasiswa Universitas Pamulang. Kegiatan PKM kali ini mengangkat tema "Upgrade Literasi Keuangan Untuk Meningkatkan Kualitas Keuangan di masa New Normal". Sebagai Narasumber Wirawan Suryanto, S.E., M.M menyampaikan "literasi keuangan merupakan kombinasi dari kesadaran, pengetahuan, keterampilan, sikap dan perilaku yang perlu dimiliki seseorang untuk membuat keputusan keuangan yang sehat dan akhirnya mencapai kesejahteraan keuangan individu". Dia juga memberikan tips-tips dalam berinvestasi yang baik antara lain: sesuaikan dengan tujuan keuangan, 


\section{JURNAL ABDIMAS

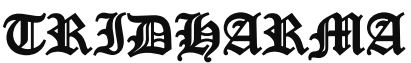

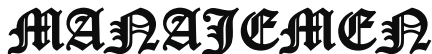

P-ISSN 2615-6849, E-ISSN 2622-3686

Jurnal ABDIMAS Vol. 1,No. 3,September 2020,Hal (75-84)

@ Prodi Manajemen Fakultas Ekonomi Universitas Pamulang

Email: abdimasjurnal.unpam@gmail.com Telp: (021) 741-2566 pahami profil risiko, ragamkan jenis asset investasi, pilih potensi keuntungan dan risiko yang wajar kemudian pelajari dan pahami investasi yang akan kita pilih. Selain hati - hati dalam memilih produk investasi, narasumber memberikan beberapa tips agar tetap sejahtera dalam hal keuangan.

Tahap yang pertama adalah membuat suatu rencana keuangan seoptimal mungkin sesuai dengan kondisi finansial masing-masing. Dimana rencana tersebut bukanlah rencana yang tinggi, dan rumit, cukup dimulai dari rencana sederhana dan bertahap dan menyesuaikan dengan keperluan dan bisa menjadi rencana yang baik.

Tahap kedua adalah mengurangi hutang. Hutang yang dimaksud pada tahap ini adalah hutang yang tidak produktif, sehingga tidak memberikan hasil yang baik untuk keuangan diri sendiri. Tunda kesenangan untuk melunasi hutang konsep ini digunakakan jika kita memiliki hutang, hendaknya segera melunasi hutang agar dapat melanjutkan kepada tahap selanjutnya. Tips terakhit pada tahap ini adalah hindari hutang sebisa mungkin.

Tahap ketiga yaitu menyiapkan dana darurat. Persiapan dana darurat ini tergantung dari beberapa faktor, diantaranya status perkawinan. Jika seorang masih single minimum menyiapkan daradarutar sebesar 3-6 bulan pengeluaran pokok. Sedangkan menikah belum memiliki anak, $6-9$ bulan. Untuk yang seudah menikah dan memiliki anak $9-12$ bulan. Perhiutngan tersebut tidak dapat dijadikan acuan kepada tiap - tiap individu, namun secara garis besar dalam hal jangka waktu perhitungan diatas dapat digunakan, Dana darurat tidak boleh digunakan kecuali untuk hal-hal yang darurat saja, tapi tidak boleh digunakan dalam hal yang kita daruratkan karena keinginan.. Tahap ini penting karena ketersediaan dana darurat menghindarkan kita dari hutang serta menjamin keadaan finansial kita tetap aman.

Tahap keempat ialah mulai berinvestasi. Tidak ada kata terlambat atau terlalu cepat dalam hal investasi, investasi pada hal yang benar dapat menyelamatkan kita dari hal - hal yang tidak kita inginkan. Sudah saatnya kita memulai investasi untuk masa depan, ataupun masa sekarang. Dalam berinvestasi tidak hanya dari sisi finansial saja, namun sisi kualitas diripun merupakan investasi yang sangat penting. Untuk yang baru akan memulai berinvestasi dapat menggunakan instrumen reksadana, saham, emas.

Tahap kelima adalah membangun aset aktif. Hal ini penting ketika akan melanjutkan ke tahap selanjutnya, dikarenakan dalam membangun aset akfi yang nantinya akan menghasilkan 


\section{JURNAL ABDIMAS

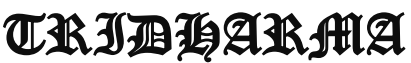

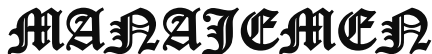

P-ISSN 2615-6849, E-ISSN 2622-3686

Jurnal ABDIMAS Vol. 1,No. 3,September 2020,Hal (75-84)

@ Prodi Manajemen Fakultas Ekonomi Universitas Pamulang

Email: abdimasjurnal.unpam@gmail.com Telp: (021) 741-2566 penghasilan pasif, tahap ini merupakan dasar dari tahap selanjutnya. Beberapa aset aktif yang bisa dimiliki diantaranya surat berharga, properti, bisnis, royalti dan sebagainya.

Tahap keenam yaitu menerima penghasilan pasif. Penghasilan pasif akan selalu ada biarpun kita tidak melakukan kegiatan, namun perlu diingat penghasilan pasif yang baik berasal dari tahap sebelumnya yaitu membangun aset aktif yang baik pula. Selain penghasilan aktif, kita juga harus memiliki penghasilan pasif. Bisa melalui bisnis online shop atau menjadi vlogger.

Tahap terakhir ialah sejahtera. Bila keenam tahapan sebelumnya dapat dilaksanakan dengan baik, maka kesejahteraan akan bisa dicapai oleh siapapun. Dengan catatan individu tersebut menjalankan secara sungguh sungguh dan komitmen dalam menjalani tiap - tiap tahapan yang dilalui.

Menurut narasumber, investasi yang paling aman pada saat pandemic ini adalah emas batangan ANTAM. Mengapa emas batangan? Karena sifatnya yang bisa melindungi dari inflasi dan penurunan nilai mata uang. Terakhir, narasumber mengajak peserta atau mahasiswa Universitas Pamulang untuk membuat skala prioritas mulai dari yang terpenting sampai dengan yang tidak penting (buat urutannya) dengan mengoptimalkan perencanaan keuangan di masa produktif dengan cara mengatur keuangan, berinvestasi dan yang paling penting diimbagi dengan pemenuhan kebutuhan pokok. Setelah narasumber menyampaikan ilmunya, kemudian perwakilan dari mahasiswa Universitas Pamulang menyampaikan rasa terima kasihnya kepada kegiatan PKM ini, karena bagi mereka di tengah pandemic ini kegiatan seperti ini sangat bermanfaat mengingat sudah dari bulan Maret 2020 mereka belajar dengan sistem daring.

\section{KESIMPULAN DAN SARAN}

\section{Kesimpulan}

Kesimpulan dari kegiatan pengabdian kepada masyarakat ini adalah bagaimana membuat perencanaan keuangan yang baik sesuai dengan kondisi finansial kita. Jangan sampai apa yang didapatkan lebih sedikit dari apa yang dikeluarkan. Investasi yang dilakukan harus sesuai dengan tujuan keuangan. Selain itu perlu mempelajari dan memahami risiko investasi yang sedang atau akan dijalankan. Pilihlah investasi yang wajar keuntungan dan risikonya. Jangan pernah membandingkan hidup kita dengan hidup orang lain. Hiduplah sesuai dengan kemampuan agar tenang dan damai menjalani kehidupan.

\section{Saran}

Saran untuk kegiatan PKM kedepanya adalah sebagai berikut: 


\section{JURNAL ABDIMAS

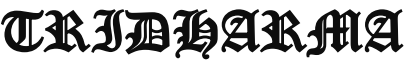

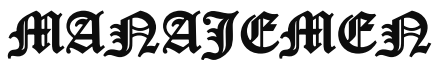

P-ISSN 2615-6849, E-ISSN 2622-3686

Jurnal ABDIMAS Vol. 1,No. 3,September 2020,Hal (75-84)

@Prodi Manajemen Fakultas Ekonomi Universitas Pamulang

Email: abdimasjurnal.unpam@gmail.com Telp: (021) 741-2566
1. Perlunya dilakukan kegiatan rutin agar selalu memahami literasi keuangan yang berkualitas meskipun dalam era new normal.

2. Peserta Seminar perlu belajar tentang literasi keuangan dengan rutin

3. Melatih siswa menuangkan ide dalam membuat kreatifitas atau inovasi terhadap barang dan jasa, membentuk kemandirian, melatih masyarakat besosialisasi dengan lingkungan, dan yang paling utama adalah meningkatkan kualitas literasi keuangannya.

\section{DAFTAR PUSTAKA.}

Kay, Janet. 2013. Pendidikan Anak Usia Dini. Yogyakarta: Kanisius.

Kemendikbud, Enam Komponen Literasi Dasar. Jendela Pendidikan dan Kebudayaan. Vol. VI bulan

Oktober 2016.

Pasaribu, V. L. D., Susanti, F., \& Hartuti, E. T. K. (2019). Memotivasi Siswa dan Siswi SMK Letris Indonesia di Dalam Menentukan Pilihan Untuk Melanjutkan Pendidikan Atau Bekerja Setelah Lulus Sekolah. Jurnal Pengabdian Dharma Laksana, 1(2), 161-172.

Pasaribu, V. L. D., Agrasadya, A., Shabrina, N., \& Krisnaldy, K. (2020). MENJADI ENTERPRENEUR MUDA YANG MEMILIKI JIWA LEADERSHIP UNTUK MENGHADAPI MASA DEPAN. Abdi Laksana, I(1).

Pasaribu, V. L. D., Elburdah, R. P., Sudarso, E., \& Fauziah, G. (2020). PENGGUNAAN MANAJEMEN WAKTU TERHADAP PENINGKATAN PRESTASI BELAJAR DI SMP ARAISIYAH. Jurnal ABDIMAS Tri Dharma Manajemen, l(1).
Pasaribu, V. L. D., Sulaiman, S., Sutiman, S., Thaharudin, T., \& Purnomo, B. Y. (2020). PENGENALAN LETAK POSYANDU TERDEKAT DIKELURAHAN PISANGAN DENGAN MANAJEMEN PEMASARAN REVOLUSI 4.0 UNTUK MENINGKATKAN PENGETAHUAN MASYARAKAT LETAK DAN FUNGSI POSYANDU TERDEKAT PADA KELURAHAN PISANGAN. DEDIKASI PKM, 1(1), 105-110.

Pasaribu, V. L. D., Oktrima, B., Prabowo, B., Arianto, N., \& Haryoko, U. B. (2020). PROGAM PENDAMPINGAN DAN PENYELENGGARAAN

PENDIDIKAN ANAK PADA USIA DINI TERHADAP PRESTASI BELAJAR DILINGKUNGAN RT 020 RW 009. KEL GIRI PENI. KEC WATES. YOGYAKARTA. JURNAL LOKABMAS KREATIF, 1(1), 71-75

Santrock, John. W. 2011. Perkembangan Masa Hidup. Jilid I. Terj. Benedictine Wisdyasinta. Jakarta: Erlangga.

Sujiono, Yuliani Nurani. 2009. Konsep Dasar Pendidikan Anak Usia Dini. Jakarta: Indeks. https://www.ojk.go.id/

\section{DOKUMENTASI KEGIATAN}

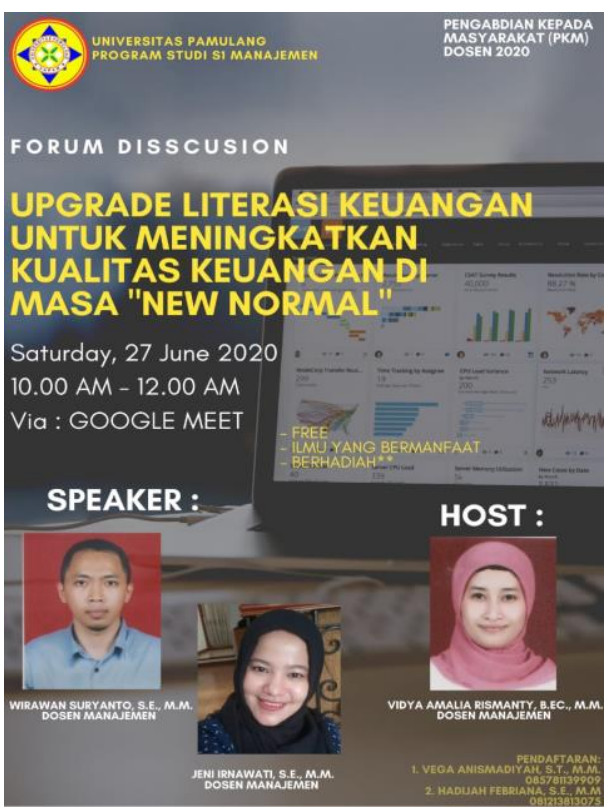




\begin{tabular}{|c|c|}
\hline JURNAL ABDIMAS & P-ISSN 2615-6849, E-ISSN 2622-3686 \\
\hline 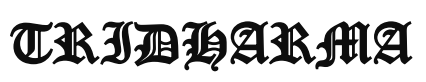 & Jurnal ABDIMAS Vol. 1,No. 3,September 2020,Hal (75-84) \\
\hline 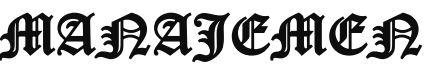 & Email: abdimasjurnal.unpam@gmail.com Telp: (021) 741-2566 \\
\hline
\end{tabular}
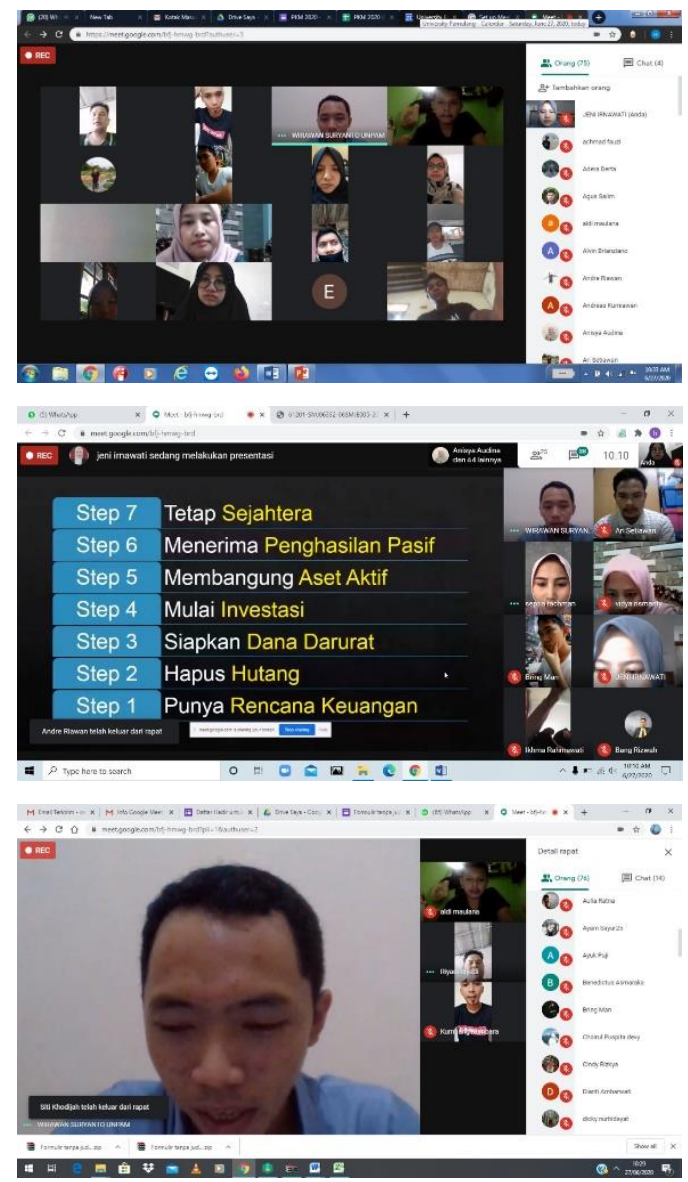